\title{
PEMODELAN MATEMATIKA PENYEBARAN PERILAKU MEROKOK BERDASARKAN FAKTOR EKONOMI DAN FAKTOR PSIKOLOGI
}

Desi Marida Babis ${ }^{1}$, Elinora Naikteas Bano ${ }^{1 *}$, Sulasri Suddin ${ }^{2}$, Leonardus Frengky Obe

${ }^{1}$ Program Studi Matematika, Fakultas Pertanian, Universitas Timor, Kefamenanu, TTU-NTT, Indonesia, * email korespondensi: iranaikteas@gmail.com

${ }_{2}^{2}$ Program Studi Pendidikan Matematika, Fakultas Ilmu Pendidikan, Universitas Timor, Kefamenanu, TTU-NTT, Indonesia.

\section{Article Info}

Article history:

Received: 21 November 2021

Received in revised form: 30 November 2021

Accepted: 17 Desember 2021

\section{Doi: https://doi.org/10.32938/slk.v4i2.1541} Keywords:

Bilangan reproduksi, Faktor ekonomi

Faktor psikologi,

Merokok

\section{Abstrak}

Merokok merupakan aktivitas membakar tembakau kemudian menghisap asapnya dan mengeluarkannya kembali lewa mulut. Peringatan bahaya merokok sudah sering disampaikan, namun perilaku merokok masih sulit untuk dikendalikan hingga saat ini. Data Survei Sosial Ekonomi Nasional, ada peningkatan prevalensi perokok usia lebih dari 15 tahun, yaitu 27\%. Pada tahun 2015, sekitar 72 juta dari 184 juta populasi dengan usia lebih dari 15 tahun merupakan perokok. Usia rata-rata mulai merokok setiap hari adalah 17,6 tahun. Hal ini membuktikan bahwa terdapat jutaan orang yang mengonsumsi dan menikmati rokok. Matematika merupakan salah satu ilmu yang dapat menganalisa masalah yang terjadi dalam kehidupan dengan menggunakan pemodelan matematika. Salah satu masalah yang dapat dikaji dengan model matematika adalah penyebaran perilaku merokok. Penelitian ini mengkaji penyebaran perilaku merokok berdasarkan faktor ekonomi dan faktor psikologi. Model ini membagi populasi menjadi 4 subpopulasi yaitu subpopulasi yang berpotensi menjadi perokok $(S)$, subpopulasi yang hanya coba-coba merokok $(D)$, subpopulasi perokok $(A)$, dan yang telah berhenti merokok $(R)$. Kestabilan titik ekulibrium bebas merokok didapatkan dengan melakukan pelinearan terhadap persamaan yang akan diperoleh matriks Jacobian kemudian akan didapatkan nilai eigen. Bilangan reproduksi dasar yang merupakan ambang batas penyebaran perilaku merokok dimana perilaku merokok akan hilang jika $R_{0}<1$ dan akan endemik saat $R_{0}>1 \odot 2021$ dipublikasikan oleh JSLK.

\section{Pendahuluan}

Merokok adalah aktivitas membakar tembakau, kemudian menghisap asapnya dan mengeluarkannya kembali melalui mulut. Perilaku merokok in dilakukan sebagai suatu cara untuk menikmati tembakau. Merokok telah diketahui menjadi faktor resiko karena mengandung zat-zat kimia yang dapat memperburuk kesehatan. Peringatan bahaya merokok sudah sering disampaikan, namun perilaku merokok masih sulit untuk dikendalikan hingga saat ini.

Data Survei Sosial Ekonomi Nasional (Susenas), ada peningkatan prevalensi perokok usia lebih dari 15 tahun, yaitu 27\% (Kementrian Kesehatan RI, 2015). Pada tahun 2015, sekitar 72 juta dari 184 juta populasi dengan usia lebih dari 15 tahun merupakan perokok (WHO, 2015). Usia rata-rata mula merokok setiap hari adalah 17,6 tahun (WHO, 2018). Hal ini membuktikan bahwa terdapat jutaan orang yang mengonsumsi dan menikmati rokok.

Matematika merupakan salah satu ilmu yang dapat menganalisa masalah yang terjadi dalam kehidupan dengan menggunakan pemodelan matematika. Salah satu masalah yang dapat dikaji dengan model matematika adalah penyebaran perilaku merokok. Penyebaran perilaku merokok dapa dikontruksi berdasarkan konsep model Susceptible Infected Recovered (SIR), yang pertama kali diperkenalkan oleh Kermack McHendrik pada tahun 1927. Model SIR digunakan untuk mengetahui penyebaran perilaku merokok dalam suatu populasi yang akan dibentuk suatu sistem persamaan diferensial yang akan dicari titik ekulibriumnya. Setelah dicari titik ekulibriumnya, akan dicari analisis kestabilan terhadap titik ekulibrium dan bilangan reproduksi dasar, dimana bilangan reproduksi dasar merupakan ambang batas penyebaran perilaku merokok.

Penelitian model penyebaran perilaku merokok sudah diperkenalkan oleh (Govan \& Ratianingsih, 2016), dengan memperhatikan faktor biologis dan faktor lingkungan sosial. Secara biologis, nikotin yang terkandung dalam rokok tersebut akan menekan kemampuan otak untuk mengalami kenikmatan, sehingga perokok akan selalu membutuhkan kadar nikotin yang semakin tinggi untuk mencapai tingkat kepuasan dan ketergantungan seseorang pada rokok. Secara umum menurut Kurt Lewin (Komasari \& Helmi, 2000) perilaku merokok merupakan fungsi dari lingkungan dan individu yang artinya perilaku merokok selain disebabkan faktor-faktor dari dalam diri, juga disebabkan faktor lingkungan sosial.

Faktor-faktor lain yang mempengaruhi penyebaran perilaku merokok adalah faktor ekonomi dan faktor psikologi. Secara ekonomi, merokok dapa membebani keuangan yang ditanggung oleh perokok karena sudah menjadi kebutuhan pokok dimana jika tuntutan tersebut tidak terpenuhi dapa mempengaruhi kondisi psikologi yang menyebabkan perokok tersebu mengalami perasaan tidak nyaman seperti cemas, merasa tertekan, sulit mengendalikan diri atau mudah marah, mudah putus asa akhirnya depresi. Para pecandu rokok juga memiliki resiko lebih besar untuk mengalami gangguan tidur, penurunan kemampuan mengingat tugas-tugas sederhana, serta mendorong munculnya perilaku kompulsif. Berdasarkan masalah tersebut, maka penulis tertarik untuk melakukan penelitian dengan judul "Pemodelan Matematika Penyebaran Perilaku Merokok Berdasarkan Faktor Ekonomi dan Faktor Psikologi".

\section{Metode}

Metode yang digunakan dalam penulisan ini adalah studi pustaka yang diperoleh dari beberapa sumber referensi yaitu buku-buku referensi, jurnal-jurna ilmiah, dan artikel web yang berhubungan dengan penyebaran perilaku merokok. Kajian mengenai model matematika penyebaran perilaku merokok berdasarkan faktor ekonomi dan faktor psikologi bersifat penelitian murni atau penelitian dasar. Langkah-langkah dalam penelitian mengenai model penyebaran perilaku merokok berdasarkan faktor ekonomi dan faktor psikologi adalah sebagai berikut: menentukan titik ekulibrium model, menentukan nilai eigen dan vektor eigen, linearisasi, menentukan kestabilan titik ekuilibrium, dan menentukan bilangan reproduksi dasar dengan Next Generation Matrix.

\section{Hasil dan Pembahasan}

3.1 Model Matematika Penyebaran Perilaku Merokok

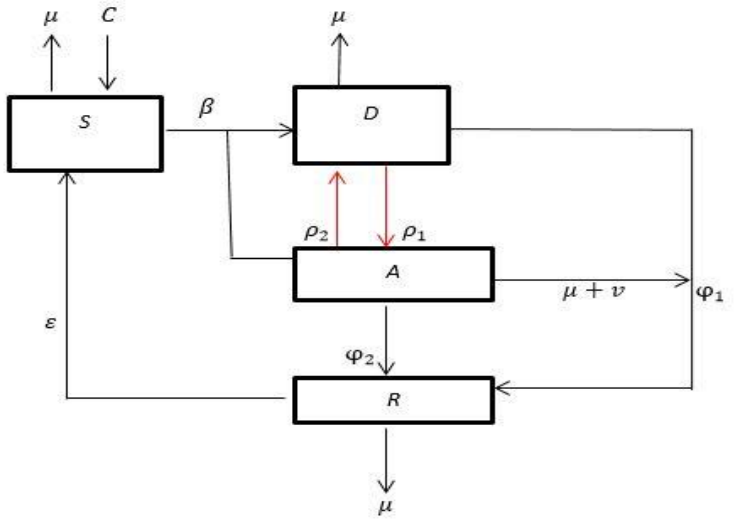

Gambar 1. Model Penyebaran Perilaku Merokok Berdasarkan Faktor Ekonomi dan Faktor Psikologi

Melalui diagram alir pada Gambar 1 populasi manusia dibagi menjadi 4 sub populasi yaitu: subpopulasi yang berpotensi menjadi perokok $S(t)$ subpopulasi yang hanya coba-coba merokok $D(t)$, subpopulasi $A(t)$, dan sub populasi yang sembuh dari pengaruh rokok, dibangun dalam suatu model matematika dalam bentuk sistem persamaan diferensial tak linear sebagai berikut:

$$
\begin{aligned}
& \frac{d S}{d t}=C-(\beta A+\mu) S+\varepsilon R \\
& \frac{d D}{d t}=\beta S A+\rho_{2} A-\left(\rho_{1}+\varphi_{1}+\mu\right) D \\
& \frac{d A}{d t}=\rho_{1} D-\left(\mu+v+\varphi_{2}+\rho_{2}\right) A \\
& \frac{d R}{d t}=\varphi_{1} D+\varphi_{2} A-(\varepsilon+\mu) R
\end{aligned}
$$

Keterangan:

$\mu \quad=$ Menyatakan laju kematian alami

$c \quad=$ Menyatakan individu baru yang masuk ke sub populasi yang berpotensi menjadi perokok

$\beta=$ = Menyatakan laju penyebaran perilaku merokok

$\rho_{1} \quad=$ Menyatakan laju penyebaran perilaku merokok dari subpopulasi coba-coba ke sub populasi perokok (Faktor Ekonomi)

$\rho_{2} \quad=$ Menyatakan laju ketergantungan (Faktor Psikologi)

$v \quad=$ Menyatakan laju transfer sub populasi penularan.

$\varphi_{1} \quad=$ Laju kesembuhan dari subpopulasi yang hanya coba-coba merokok ke sub populasi yang sembuh dari pengaruh rokok.

$\varphi_{2} \quad=$ Laju kesembuhan dari subpopulasi perokok ke sub populasi yang sembuh dari pengaruh rokok.

= Laju penularan dari subpopulasi yang sembuh dari pengaruh rokok ke sub populasi yang berpotensi menjadi perokok. 


\subsection{Penentuan Titik Ekuilibrium}

Titik ekuilibrium diperoleh dengan beberapa tahapan dan salah satunya adalah dengan membuat ruas kiri sistem persamaan (1) sama dengan nol yaitu sebagai berikut:

Menurut (Perko, 2001) titik ekuilibrium diperoleh dengan dengan syarat:

$$
\frac{d S}{d t}=\frac{d D}{d t}=\frac{d A}{d t}=\frac{d R}{d t}=0
$$

Sehingga diperoleh dua titik ekuilibrium. Titik ekuilibrium yang pertama menyatakan populasi bebas merokok $T_{1}=\left\{S=\frac{C}{\mu}, D=0, A=0, R=0\right\}$ dan titik ekulibrium kedua menyatakan keendemikan perilaku merokok dalam populasi $T_{2}=\{\dot{S}, \dot{D}, \dot{A}, \dot{R}\}$

dengan

$$
\begin{aligned}
& \dot{S}=\frac{a_{0} a_{1-} \rho_{1} \rho_{2}}{\beta \rho_{1}} \\
& \dot{D}=-\frac{a_{1} a_{2}\left(\beta \rho_{1} C-\mu \rho_{1} \rho_{2}+\mu a_{0} a_{1}\right)}{\beta\left(-a_{2} \rho_{1} \rho_{2}+a_{2} a_{0} a_{1}-\varepsilon a_{1} \varphi_{1}-\varepsilon \rho_{1} \varphi_{2}\right)} \\
& \dot{A}=-\frac{a_{2}\left(-\beta \rho_{1} C-\mu \rho_{1} \rho_{2}+\mu a_{0} a_{1}\right)}{\beta\left(-a_{2} \rho_{1} \rho_{2}+a_{2} a_{0} a_{1}-\varepsilon a_{1} \varphi_{1}-\varepsilon \rho_{1} \varphi_{2}\right)} \\
& \dot{R}=-\frac{\left(-c \mu \beta \rho_{1}-\mu \rho_{1} \rho_{2}+\mu a_{0} a_{1}\right)\left(\varphi_{1} a_{1}+\varphi_{2} \rho_{1}\right)}{\beta\left(-a_{2} \rho_{1} \rho_{2}+a_{2} a_{0} a_{1}-\varepsilon a_{1} \varphi_{1}-\varepsilon \rho_{1} \varphi_{2}\right)}
\end{aligned}
$$

\subsection{Menentukan Bilangan Reproduksi Dasar $\left(\boldsymbol{R}_{0}\right)$}

Bilangan reproduksi dasar didapatkan dengan membangun matriks yang menunjukkan rata rata jumlah individu terinfeksi baru dengan metode Next Generation Matrix (NGM) seperti yang tertuang dalam (Driessche \& Watmough, 2002). Misalkan $\boldsymbol{x}=(D, A)^{T}$, sehingga persamaan (1) dapat dituliskan sebagai:

$$
\frac{d x}{d t}=F(\boldsymbol{x})-V(\boldsymbol{x})
$$

dengan $F(\boldsymbol{x})$ adalah Matriks transmisi yaitu matriks yang terdapat laju individu baru karena kontak dan $V(\boldsymbol{x})$ adalah Matriks transisi yaitu matriks yang terdapat laju transfer masuk dan keluar sub populasi terinfeksi. Sehingga didapatkan:

$$
\begin{aligned}
F(\boldsymbol{x}) & =\left[\begin{array}{l}
F_{1} \\
F_{2}
\end{array}\right]=\left[\begin{array}{c}
\beta S A \\
0
\end{array}\right] \\
V(\boldsymbol{x}) & =\left[\begin{array}{c}
\left(\rho_{1}+\varphi_{1}+\mu\right) D-\rho_{2} A \\
\left(\mu+v+\varphi_{2}+\rho_{2}\right) A-\rho_{1} D
\end{array}\right] \\
T & =\left[\begin{array}{ll}
F_{1} D & F_{1} A \\
F_{2} D & F_{2} A
\end{array}\right]=\left[\begin{array}{rr}
0 & \beta S \\
0 & 0
\end{array}\right] \\
\varepsilon & =\left[\begin{array}{ll}
V_{1} D & V_{2} A \\
V_{2} D & V_{2} A
\end{array}\right] \\
= & {\left[\begin{array}{ll}
\left(\rho_{1}+\varphi_{1}+\mu\right) \\
-\rho_{1}
\end{array}\right.}
\end{aligned}
$$

Dengan mensubsitusikan titik ekuilibrium bebas merokok pada $T$ dan $\varepsilon$ diperoleh

$$
\begin{aligned}
& T=\left[\begin{array}{ll}
0 & \frac{\beta c}{\mu} \\
0 & 0
\end{array}\right], \text { dan } \varepsilon \\
& =\left[\begin{array}{l}
\left(\rho_{1}+\varphi_{1}+\mu\right) \\
-\rho_{1}
\end{array}\right.
\end{aligned}
$$

The next generation matrix (NGM) yaitu :

$$
\begin{aligned}
T \varepsilon^{-1} & =\left[\begin{array}{cc}
0 & \frac{\beta C}{\mu} \\
0 & 0
\end{array}\right]\left[\begin{array}{cc}
\frac{1}{\rho_{1}+\varphi_{1}+\mu} & \frac{-\rho_{1}}{\left(\rho_{1}+\varphi_{1}+\mu\right)\left(\mu+v+\varphi_{2}+\rho_{2}\right)} \\
\frac{-\rho_{2}}{\left(\rho_{2}+\varphi_{2}+\mu\right)\left(\mu+v+\varphi_{2}+\rho_{2}\right)} & \frac{1}{\left(\mu+v+\varphi_{2}+\rho_{2}\right)}
\end{array}\right] \\
& =\left[\begin{array}{cc}
-\frac{\beta C \rho_{2}}{\mu\left(\rho_{1}+\varphi_{1}+\mu\right)\left(\mu+v+\varphi_{2}+\rho_{2}\right)} & \frac{\beta c}{\mu\left(\mu+v+\varphi_{2}+\rho_{2}\right)} \\
0 & 0
\end{array}\right]
\end{aligned}
$$

3.4 Ambang batas epidemik $\left(R_{0}\right)$

Bilangan $R_{0}$ yaitu nilai eigen terbesar, sehingga:

$$
\begin{aligned}
& R_{0} \text { yaitu nilai eigen terbesar, sehingga: } \\
& R_{0}=\frac{\beta C \rho_{2}}{\mu\left(\rho_{1}+\varphi_{1}+\mu\right)\left(\mu+v+\varphi_{2}+\rho_{2}\right)}
\end{aligned}
$$

3.5 Kestabilan Titik Ekuilibrium Bebas Merokok $\left(T_{1}\right)$

Misalkan ruas kanan persamaan dapat ditulis dalam bentuk:

$$
\begin{aligned}
& \frac{d S}{d t}=\dot{x_{1}}=f_{1}(x) ; f_{1}(S, D, A, R)=C-(\beta A+\mu) s+\varepsilon R \\
& \frac{d D}{d t}=\dot{x_{2}}=f_{2}(x) ; f_{2}(S, D, A, R)=\beta s A+\rho_{2} A-\left(\rho_{1}+\varphi_{1}+\mu\right) D \\
& \frac{d A}{d t}=\dot{x_{3}}=f_{3}(x) ; f_{3}(S, D, A, R)=\rho_{1} D-\left(\mu+v+\varphi_{2}+p_{2}\right) \\
& \frac{d R}{d t}=\dot{x_{4}}=f_{4}(x) ; f_{4}(S, D, A, R)=\varphi_{1} D+\varphi_{2} A-(\varepsilon+\mu) R
\end{aligned}
$$

Penentuan kestabilan di sekitar titik ekuilibrium bebas merokok $\left(\boldsymbol{T}_{\mathbf{1}}\right)$, terlebih dahulu dilakukan pelinearan terhadap persamaan di atas, kemudian diperoleh matriks Jacobi:

$$
\boldsymbol{J}=\left[\begin{array}{llll}
\frac{\partial f_{1}}{d S} & \frac{\partial f_{1}}{d D} & \frac{\partial f_{1}}{d A} & \frac{\partial f_{1}}{d R} \\
\frac{\partial f_{2}}{d S} & \frac{\partial f_{2}}{d D} & \frac{\partial f_{2}}{d A} & \frac{\partial f_{2}}{d R} \\
\frac{\partial f_{3}}{d S} & \frac{\partial f_{3}}{d D} & \frac{\partial f_{3}}{d A} & \frac{\partial f_{3}}{d R} \\
\frac{\partial f_{4}}{d S} & \frac{\partial f_{4}}{d D} & \frac{\partial f_{4}}{d A} & \frac{\partial f_{4}}{d R}
\end{array}\right]
$$

Nilai eigen dari Matriks $J_{T 1}$, dapat dicari dengan menentukan det $\left(J_{T 1}-\right.$ $\lambda I)=0$ dengan $\lambda$ adalah Nilai eigen dan $I$ adalah matriks identitas sehingga diperoleh

$$
\operatorname{det}\left(J_{T 1}-\lambda I\right)=0
$$

Nilai $\lambda_{1}, \lambda_{2}, \lambda_{3}$, dan $\lambda_{4}$ dapat ditentukan sebagai berikut:

$$
\lambda_{1}=-\mu
$$

$\lambda_{2}=-\varepsilon+\mu$

$\lambda_{3}=-\mu \sqrt{2\left(\rho_{1} \varphi_{1}-\rho_{1} v-2 \rho_{1} \varphi_{1}-\rho_{1} \varphi_{2}-\rho_{1} \rho_{2}-\rho_{1} \mu-\varphi_{1} v-\varphi_{1} \varphi_{2}\right)}$

$\lambda_{4}=\frac{-\left(\rho_{1}+\varphi_{1}+2 \mu+v+\varphi_{2}+\rho_{2}\right)}{2}$

$-\sqrt{\rho_{1}^{2}+\varphi_{1}^{2}+v^{2}+\varphi_{2}^{2}+\rho_{2}+2 \rho_{1} \varphi_{1}+2 \rho_{1} v-2 \rho_{1} \varphi_{2}+2 \rho_{1} \rho_{2}-2 \varphi_{1} \mu-2 \varphi_{1} v-2 \varphi_{1} \varphi}$

Berdasarkan nilai eigen yang didapatkan, diketahui bahwa $\lambda_{1}, \lambda_{2}, \lambda_{3}, \lambda_{4},<0$ dan bernilai negatif sehingga jenis kestabilan titik ekuilibrium bebas merokok pada model penyebaran perilaku merokok stabil asimtotik.

\subsection{Pengaruh Faktor Ekonomi $\left(\rho_{1}\right)$ dan Faktor Psikologi $\left(\rho_{2}\right)$ yang mempengaruhi Penyebaran Perilaku Merokok}

Tabel 1 Pengaruh Faktor Ekonomi $\left(\boldsymbol{\rho}_{\mathbf{1}}\right)$ terhadap nilai $\boldsymbol{R}_{\mathbf{0}}$.

Tabel 2 Pengaruh Faktor Psikologi

\begin{tabular}{|c|c|c|}
\hline No. & $\begin{array}{c}\text { Jumlah } \\
\text { (Orang) }\end{array}$ & Nilai $\boldsymbol{R}_{\mathbf{0}}$ \\
\hline 1. & 0.0002 & 3444,6 \\
\hline 2. & 0.0003 & 3426,37 \\
\hline 3. & 0.0004 & 3408,34 \\
\hline 4. & 0.0005 & 3390,49 \\
\hline 7. & 0.0008 & 3338,06 \\
\hline 6. & 0.0007 & 3355,36 \\
\hline 5. & 0.0006 & 3372,84 \\
\hline
\end{tabular}
$\left(\boldsymbol{\rho}_{2}\right)$ terhadap nilai $\boldsymbol{R}_{\mathbf{0}}$

\begin{tabular}{|c|c|c|}
\hline No. & $\begin{array}{c}\text { Jumlah } \\
\text { (Orang) }\end{array}$ & Nilai $\boldsymbol{R}_{\mathbf{0}}$ \\
\hline 1. & 0.0002 & 0.586989 \\
\hline 2. & 0.0003 & 0.876553 \\
\hline 3. & 0.0004 & 1.16354 \\
\hline 4. & 0.0005 & 1.44799 \\
\hline 5. & 0.0006 & 1.72994 \\
\hline 6. & 0.0007 & 2.00941 \\
\hline & & \\
\hline & & \\
\hline & & \\
\hline
\end{tabular}

Berdasarkan Tabel 1, dapat diperhatikan bahwa pengaruh faktor ekonomi $\left(\rho_{1}\right)$ terhadap penyebaran perilaku merokok semakin menurun dimana semakin banyak perokok maka akan semakin kecil pula nilai $R_{0}$ sehingga perilaku merokok akan hilang dari populasi, sedangkan pada Tabel 2 faktor psikologi $\rho_{2}$ dapat dilihat bahwa dimana semakin banyak perokok maka akan semakin tinggi pula tingkat depresi yang mempengaruhi psikologi yang menyebabkan nilai $R_{0}$ semakin meningkat.

\section{Simpulan}

Berdasarkan analisis dan pembahasan yang dilakukan terhadap model matematika penyebaran perilaku merokok berdasarkan faktor ekonomi dan faktor psikologi dapat disimpulkan:

1. Model yang dihasilkan mampu menggambarkan penyebaran perilaku merokok berdasarkan faktor ekonomi dan faktor psikologi.

2. Titik ekulibrium yang diperoleh ada dua yaitu titik ekulibrium bebas merokok dan titik ekulibrium endemik.

3. Pengaruh faktor ekonomi $\left(\rho_{1}\right)$ terhadap penyebaran perilaku merokok semakin menurun dimana semakin banyak perokok maka akan semakin kecil pula nilai $R_{0}$ sehinngga perilaku merokok akan hilang dari populasi sedangkan faktor psikologi $\left(\rho_{2}\right)$ terhadap penyebaran perilaku merokok sangat besar, dimana semakin banyak perokok maka akan semakin besar pula tingkat depresi yang mempengaruhi Psikologi yang menyebabkan nilai $R_{0}$ semakin meningkat. 
4. $R_{0}>1$ artinya setiap perokok dapat menularkan perilaku merokoknya kepada lebih dari satu perokok baru sehingga pada akhirnya penyebaran perilaku merokok akan meluas atau endemik.

\section{Pustaka}

Driessche, P. van den \& Watmough, J. 2002. Reproduction numbers and subthreshold endemic equilibria for compartmental models of disease transmission. Mathematical Biosciences, 29.

Govan, G. \& Ratianingsih, R. 2016. Membangun Model Penyebaran Perilaku Merokok Berdasarkan Faktor Biologis dan Faktor Lingkungan Sosial. JURNAL ILMIAH MATEMATIKA TERAPAN, 13.
Komasari, D. \& Helmi, A.F. 2000. FAKTOR-FAKTOR PENYEBAB PERILAKU MEROKOK PADA REMAJA. JURNAL PSIKOLOGI, $37-47$.

Perko, L. 2001. Differential Equations and Dynamical Systems (Third Edition). Berlin-New York: Springer-Verlag New York Berlin Heidelberg.

WHO, W. 2015. WHO Global Report On Trends In Prevalence Of Tobacco Smoking 2015. WHO.

WHO, W. 2018. Heart Diasease and Stroke are the Commonest Ways by Which

Tobacco Kills People. WHO. Tersedia di http://www.searo.who.int/tobacco/data/ino_rtc_reports. 